\title{
Convectively Induced Stabilizations and Subsequent Recovery with Supercell Thunderstorms during the Mesoscale Predictability Experiment (MPEX) $\mathscr{O}$
}

\author{
ROBERT J. TRAPP \\ Department of Atmospheric Sciences, University of Illinois at Urbana-Champaign, Urbana, Illinois \\ JOSEPH M. WOZNICKI ${ }^{\mathrm{a}}$ \\ Department of Earth, Atmospheric, and Planetary Sciences, Purdue University, West Lafayette, Indiana
}

(Manuscript received 19 July 2016, in final form 15 November 2016)

\begin{abstract}
The adiabatic and diabatic processes inherent to midlatitude deep convective storms are well known to modify the atmospheric temperature, moisture, and winds especially within horizontal scales equivalent to a Rossby radius of deformation. Such modifications, or "feedbacks," induced by supercell thunderstorms were a particular focus of the Mesoscale Predictability Experiment (MPEX), owing to the unique supercell dynamics and associated supercell intensity and longevity. During the MPEX field phase, which was conducted 15 May-15 June 2013 within the Great Plains region of the United States, radiosonde observations collected in immediate supercell wakes exhibited temperature lapse rates that were qualitatively and quantitatively similar to preconvective lapse rates above the boundary layer.

Complementary idealized model simulations were used to confirm that there was little residual effect of the supercell in the wake of the moving storm except within the area occupied by the surface cold pool, and where stabilizations were induced adiabatically by transient gravity wave disturbances. The persistency of the (i) cold pool, and its inhibition to surface-based convection, depended on the evolving cold pool strength and environmental winds; and (ii) gravity wave effects depended on the Doppler-shifted phase speed relative to the moving storm. Otherwise, recovery of the wake environment to its preconvective state occurred approximately over a time scale defined by the updraft length scale and horizontal advective velocity scale.
\end{abstract}

\section{Introduction}

In addition to the temperature and moisture modifications that result from vertical mixing by updrafts and downdrafts, deep convective clouds diabatically heat the atmosphere through condensation, freezing, and deposition in updrafts, and diabatically cool the atmosphere through evaporation, melting, and sublimation in precipitating downdrafts. The combination of these

Supplemental information related to this paper is available at the Journals Online website: http://dx.doi.org/10.1175/ MWR-D-16-0266.s1.

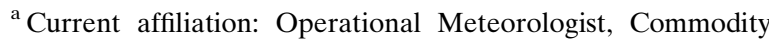
Weather Group, LLC, Bethesda, Maryland.
}

Corresponding author e-mail: Robert J. Trapp, jtrapp@ illinois.edu effects composes what is often colloquially referred to as "convective overturning." For example, consider the following excerpt from a (modified) forecast discussion:

\section{IT APPEARS THAT REDEVELOPMENT OF STORMS IN THE WAKE OF EARLIER CONVEC- TION WILL OCCUR, ALTHOUGH INSTABILITY WILL BE GREATLY REDUCED BECAUSE OF PRIOR CONVECTIVE OVERTURNING...}

The result of convective overturning would appear to be a stabilization of the local density stratification, as manifest by a relaxation of the temperature lapse rate above the boundary layer toward one of a moist-neutral parcel, and (near) elimination of convective available potential energy (CAPE) (e.g., see the review by Bretherton 1993). In this regard, convective overturning or stabilization is a feedback on the larger-scale atmosphere.

Such feedbacks induced by supercell thunderstorms have received little attention in the literature (e.g., 
Schlesinger 1990) despite the unique supercell dynamics and associated intensity and longevity. Accordingly, supercell thunderstorms were of particular interest during the Mesoscale Predictability Experiment (MPEX; Weisman et al. 2015), a field campaign conducted in 2013 throughout the Great Plains region of the United States. MPEX had three project objectives relevant to this interest: quantify the observed environmental modifications and upscale feedbacks from deep convection, and relate these back to the characteristics of the convection; evaluate model simulations of upscale feedbacks from deep convection with MPEX observations; and explore the predictability of convectively disturbed atmospheres (Weisman et al. 2015; see also Trapp et al. 2016).

These objectives are complementary to, yet different from those underlying the studies of storm-environment interactions by Brooks et al. (1993), Parker (2014), and recently by Nowotarski and Markowski (2016). The focus of these studies is on a storm-environment-storm feedback loop, wherein a storm modifies its neardownstream environment, which is then ingested by and modifies that same storm. Our focus is on upstream, or storm-wake modifications, and how a storm modifies the potential for subsequent convection within its previous location.

We demonstrate herein using MPEX radiosonde observations and complementary numerical model simulations that a convectively generated cold pool and its associated inhibition of surface-based convection, and upstream-propagating gravity wave disturbances and their associated adiabatic warming aloft, comprise the primary residual effects of a moving supercell.

Description of MPEX data collection strategies and data analysis approaches are given in section 2, as is the relevant information on numerical model simulations. In section 3, the results of three MPEX case analyses and complementary numerical model simulations are presented. Conclusions and implications of this work are provided in section 4 .

\section{Methodology}

\section{a. MPEX data collection and analysis}

Mobile radiosonde operations were conducted during MPEX by teams from Purdue University (PU), the National Severe Storms Laboratory (NSSL), Colorado State University (CSU), and Texas A\&M University (TAMU). Termed "upsondes" to distinguish them from the dropsondes released from National Center for Atmospheric Research (NCAR) Gulfstream V jet (see Weisman et al. 2015), these balloon-borne radiosonde observations were collected for the purpose of quantifying the preconvective mesoscale environment and the mesoscale environment that had been disturbed by subsequent convective storms. Information about the upsonde systems, data quality control, and sampling strategies is given in Trapp et al. (2016).

A particular objective of the sampling strategies was to collect coordinated upsonde data in the immediate wake of the convective storm as well as on the storm's north and/or south flanks. By wake, we are referring specifically to a geographical location that had previously been occupied by the $(\sim 5-10 \mathrm{~km})$ core of the convective storm. The nominal offset distance between the sonde release location and the near-edge of the storm's high-reflectivity core was $20 \mathrm{~km}$. This offset was used in an attempt to prevent the sondes from entering the storm proper; in practice, the offset distance depended on the local road network, availability of suitable deployment sites, etc.

Supercell thunderstorms within three intensive observing periods (IOPs) are considered here: the 19 May 2013 tornadic supercell near Shawnee, Oklahoma; the 23 May 2013 tornadic supercell east of Floydada, Texas; and the 30 May 2013 nontornadic supercell near Chickasha, Oklahoma (Fig. 1).

For the purposes of the current work, our primary comparison per IOP case is between a wake sounding (indicated by the filled black circle in Fig. 1) and a preconvective sounding in geospatial proximity (indicated by the filled red circle in Fig. 1). Three basic soundings parameters are used: CAPE, midlevel lapse rate (MLR), and deep-layer shear (DLS). CAPE $\left(\mathrm{J} \mathrm{kg}^{-1}\right)$ is computed both using a surface-based (SB) and mixed-layer (ML) parcel; $\mathrm{CAPE}_{475}$ indicates the use of an upper integration limit of $475 \mathrm{hPa}$ instead of the equilibrium level. The integration-limit modification is necessary because many of the soundings terminated before reaching the equilibrium level (EL), and $475 \mathrm{hPa}$ was below the termination level in most of the soundings. The MLR $\left({ }^{\circ} \mathrm{Ckm}^{-1}\right)$ is the difference between the temperature at $700 \mathrm{hPa}$ and that at $500 \mathrm{hPa}$, divided by the height difference between those two levels. Finally, DLS $\left(\mathrm{m} \mathrm{s}^{-1}\right)$ is the magnitude of the vector difference between the horizontal wind at $6 \mathrm{~km}$ AGL and that nearest to the ground.

\section{b. Numerical simulations of MPEX events}

Idealized numerical simulations of the MPEX events are used to help interpret the soundings. Recall that in a typical implementation of a cloud model like that developed by Klemp and Wilhelmson (1978), the initial conditions are horizontally homogeneous and defined by a preconvective sounding; the same sounding is also used to impose the lateral boundary conditions at inflow. 

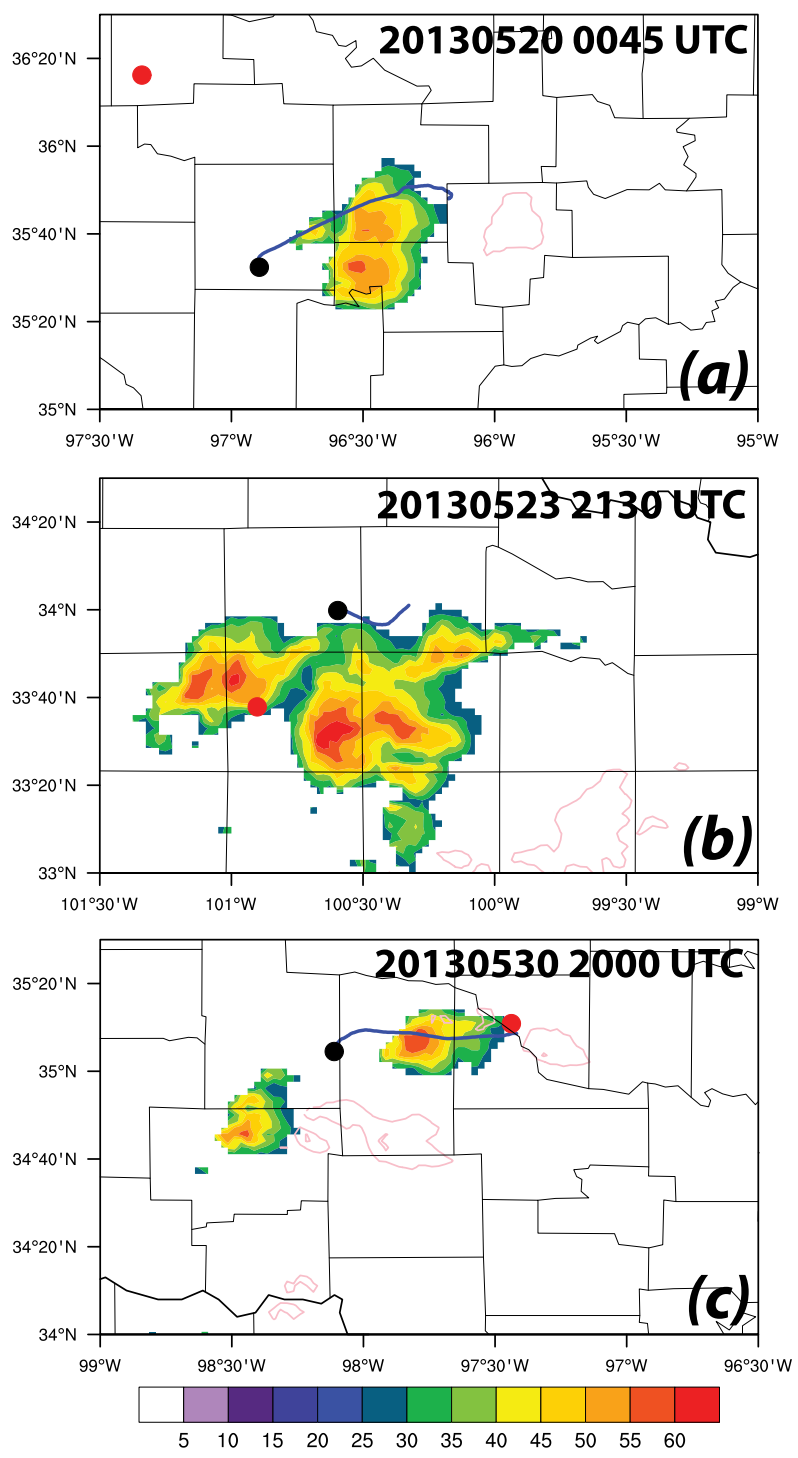

FIG. 1. Locations of upsonde observations, overlaid on composite radar reflectivity factor (dBZ): (a) 19 May, (b) 23 May, and (c) 30 May 2013. Filled black (red) circles indicate locations of supercell wake (preconvective) sampling, and blue lines indicate the trajectory of the supercell wake sounding. Pink contours are of the 45- and 60-dBZ radar reflectivity at 0145 UTC 20 May 2013 in (a), 2345 UTC 23 May 2013 in (b), and 2130 UTC 30 May 2013 in (c). (Composite reflectivity data courtesy of M. Coniglio, National Severe Storms Laboratory.)

The underlying assumption in such an implementation is that the larger-scale environment is steady over the course of the model integration, and is also free of horizontal gradients over the extent of the model domain. Radiative and land surface processes are purposely excluded from our simulations so that all modifications to the dependent variables are necessarily induced-either directly or indirectly—by the storm within the domain. Accordingly, the idealized modeling approach is particularly well suited to the study of convective stabilizations and subsequent environmental recovery.

Our simulations are conducted with the CM1 model (see Bryan and Fritsch 2002). Details of the model configuration are provided in Table 1. Limited experimentation with grid lengths of 250 and $125 \mathrm{~m}$ (see Fig. S1 in the online supplemental material) shows in particular that the primary updrafts maintain their core organization and size over a 500-125-m grid-length range, as does the surface cold pool; we use this to argue that the convective stabilization and recovery processes described below are also maintained over this range, and thus justify our use of 500-m grid lengths.

Of further note is our lack of implementation of a "domain translation" (i.e., a subtraction of an approximate storm-motion vector from the environmental wind profile). This artificially introduces near-stationarity to the domain-relative position of the storm, and therefore precludes an analysis of the local environmental recovery that follows convective stabilization.

A relevant preconvective sounding is used to represent the environment for each case (see below), with minor modifications made to the boundary layer humidity and temperature to satisfy a Richardson number criterion within CM1 and also to reduce convective inhibition (CIN). Deep convection is then initiated within each environment with the aid of a warm bubble (see Table 1). Although the entirety of the subsequent convective evolution is analyzed, our specific focus is on the time when the simulated convective storm had the greatest qualitative similarity to the MPEX storm at the time of its upsonde sampling.

\section{Results}

As noted in Weisman et al. (2015) and Trapp et al. (2016), the upsonde operations on 19 May 2013 exemplified the intended sampling strategy for upscale feedbacks. Accordingly, we use detailed analysis and simulations of this case to illustrate the essential processes common to the three aforementioned supercells, and then follow with a summary of the remaining cases to show generality of results. Additional simulations using highly idealized supercell and squall-line environments (e.g., Weisman and Klemp 1982) provide for further comparison and contrast with the MPEX cases.

\section{a. 19 May 2013 supercell}

Upsonde observations of the 19 May 2013 Shawnee, Oklahoma, supercell were coordinated at approximately 0045 UTC [Fig. 1a; see also Fig. 15 in Weisman 
TABLE 1. Details of CM1 model configuration.

\author{
Domain dimensions \\ Gridpoint spacings \\ Time step \\ Microphysical parameterization \\ Turbulence parameterization \\ Convection initiation
}

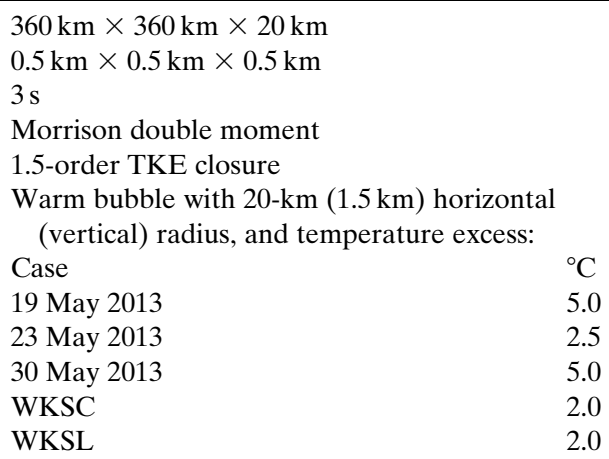

Lateral boundary condition

Upper and lower boundary conditions et al. (2015)]. This supercell spawned a tornado [EF-1 on the enhanced Fujita (EF) scale] approximately $25 \mathrm{~min}$ prior to this sampling time (and EF-4 tornado $60 \mathrm{~min}$ prior), but still had a well-defined mesocyclone (not shown) and reflectivity appendage. The supercell was additionally undergoing a split into right- and leftmoving cells at this time.

Values of sounding parameters summarized in Table 2 indicate a near-elimination of (ML and SB) $\mathrm{CAPE}_{475}$ in the supercell wake relative to that found in the preconvective environment (and on the supercell flanks; not shown). Upon inspection of the wake sounding, it is clear that much of this $\mathrm{CAPE}_{475}$ reduction is attributable to the convectively generated cold pool, which is manifest as a surface-based temperature inversion (Fig. 2). Above this rather shallow inversion, the vertical temperature structure up through $\sim 550 \mathrm{hPa}$ is qualitatively and quantitatively similar to that seen in the preconvective sounding. The stable layer at $\sim 550 \mathrm{hPa}$ was likely sampled as the sonde traversed the northern flank of the supercell (see Fig. 1a). The calculation of MLR in the wake sounding reflects this layer as well as the steep lapse rates near $700 \mathrm{hPa}$, with a $19 \%$ MLR reduction relative to the preconvective value; for reference, stabilization of the wake environment to the moist adiabatic lapse rate would have resulted in a $40 \%$ MLR reduction. Finally, the wake DLS is $21 \%$ larger than that found in the preconvective environment. Figure 2 suggests that this DLS increase is due in part to a cold-pool enhancement of the easterly component of the low-level winds.

Full interpretation of this DLS enhancement, and of the sounding parameters in general, is somewhat obscured by the fact that the supercell evolved (and other convective clouds formed nearby) during the upsonde observation, and also because the (presumed dynamically induced) supercell propagation caused the supercell's trajectory to deviate from that of the sonde. Moreover, because the time difference between the wake and preconvective soundings is approximately $6 \mathrm{~h}$, radiative and synoptic-scale dynamical forcings should have also contributed to the evolution of the environment. Thus, we now consult the numerical simulation, which does not suffer from these interpretation issues, because the sounding parameters are from instantaneous, vertical profiles, and are presented relative to a static environment.

Figure 3 provides an overview of the 19 May 2013 simulation. At $t=50$ (Fig. 3a), which is a time of

TABLE 2. Sounding parameter calculations, using MPEX data on 19 May, 23 May, and 30 May 2013. CAPE 475 is convective available potential energy $\left(\mathrm{J} \mathrm{kg}^{-1}\right)$ computed with an upper integration limit of $475 \mathrm{hPa}$, and using a surface-based (SB) and mixed-layer (ML) parcel, MLR is midlevel lapse rate $\left({ }^{\circ} \mathrm{C} \mathrm{km}^{-1}\right)$, and DLS is deep-layer wind shear $\left(\mathrm{m} \mathrm{s}^{-1}\right)$ (see text).

\begin{tabular}{lccccc}
\hline \hline & Time $(\mathrm{UTC})$ & $\mathrm{SBCAPE}_{475}\left(\mathrm{~J} \mathrm{~kg}^{-1}\right)$ & MLCAPE $_{475}\left(\mathrm{~J} \mathrm{~kg}^{-1}\right)$ & $\left.\mathrm{MLR}^{\circ} \mathrm{C} \mathrm{km}^{-1}\right)$ & $\mathrm{DLS}^{\left(\mathrm{m} \mathrm{s}^{-1}\right)}$ \\
\hline 19 May 2013: Preconvective & 1858 & 1349 & 804 & 8.51 & 2.86 \\
19 May 2013: Wake & 0045 & 14 & 19 & 8.02 & 35.6 \\
23 May 2013: Preconvective & 1759 & 534 & 266 & 8.24 & 22.9 \\
23 May 2013: Wake & 2124 & 48 & 48 & 1163 & 26.8 \\
30 May 2013: Preconvective & 1732 & 1362 & 652 & 5.81 & 24.0 \\
30 May 2013: Wake & 2000 & 1009 & & 25.9 \\
\hline
\end{tabular}



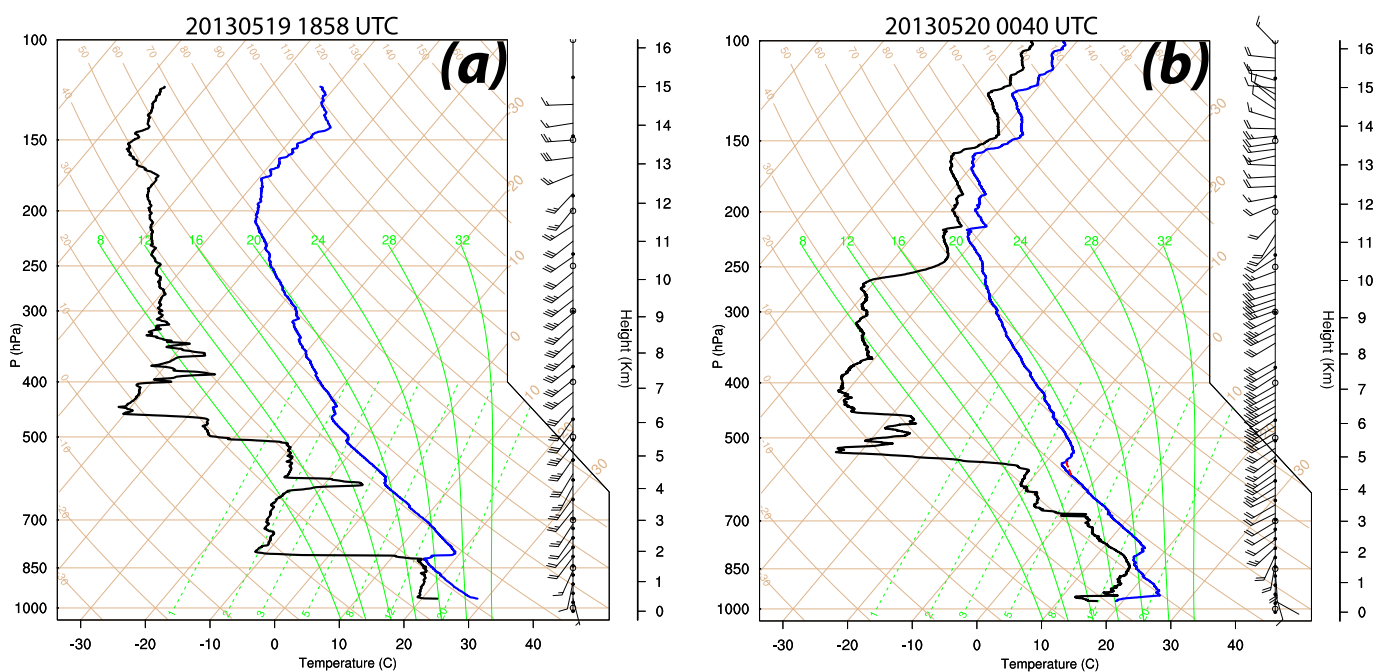

FIG. 2. Skew $T-\log p$ diagram of the (a) preconvective sounding and (b) supercell wake sounding, collected on 19 May 2013 during MPEX. One full (half) barb equates to $10(5) \mathrm{m} \mathrm{s}^{-1}$.

qualitative similarity between the simulated and observed storm, the largest CAPE reduction is in the primary downdraft as well as within the cold pool (Fig. 4a). Most importantly, there is no far-field zone of reduced CAPE that would specifically correspond to the previous locations of the supercell (and its cold pool) (see Fig. 4a), and thus of the associated previous convective stabilization. Fields of MLR and DLS similarly show that the storm-induced modifications are indeed local (i.e., within a cold-pool radius), and have little to no remnant that coincides with the history of the supercell (Figs. 4b,c). In the MLR, we see that the greatest reductions are within updrafts. For DLS, significant modifications are found on the flanks of the mesocyclonic circulations.

A time sequence of model soundings at a fixed gridpoint location $(x=51, y=86 \mathrm{~km})$ provides further insight into the nature of the convective stabilization and subsequent recovery (Fig. 5). A sounding through one of the updraft cores (Fig. 3a) at $t=50 \mathrm{~min}$

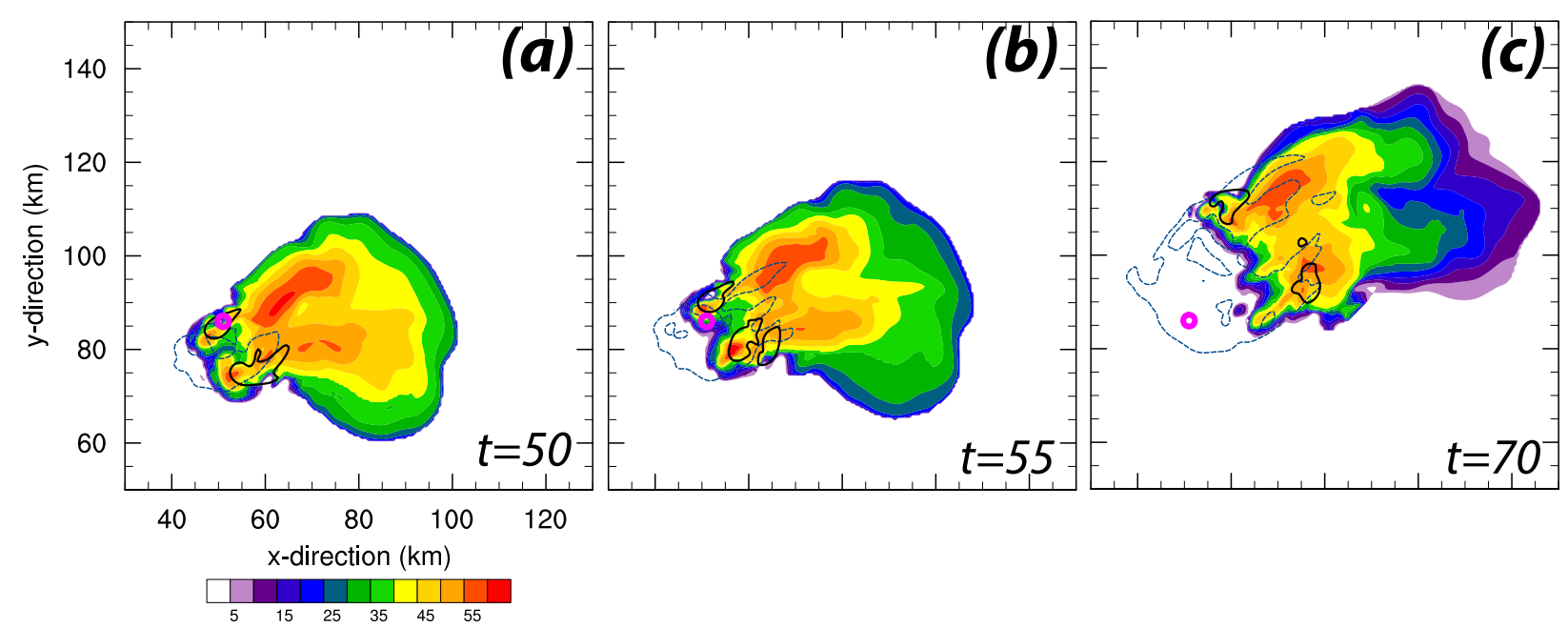

FIG. 3. Simulated radar reflectivity factor at $z=2.25 \mathrm{~km}$ (dBZ; color fill), the $10 \mathrm{~m} \mathrm{~s}^{-1}$ vertical velocity contour at $z=6.25 \mathrm{~km}$ (bold black line), and the $-1{ }^{\circ} \mathrm{C}$ perturbation potential temperature contour at $z=250 \mathrm{~m}$ (dashed blue line) from the 19 May 2013 simulation: (a) $t=50$, (b) $t=55$, and (c) $t=70 \mathrm{~min}$. The magenta circle marks the location of the gridpoint soundings in Fig. 5. Only a portion of the domain is shown. 


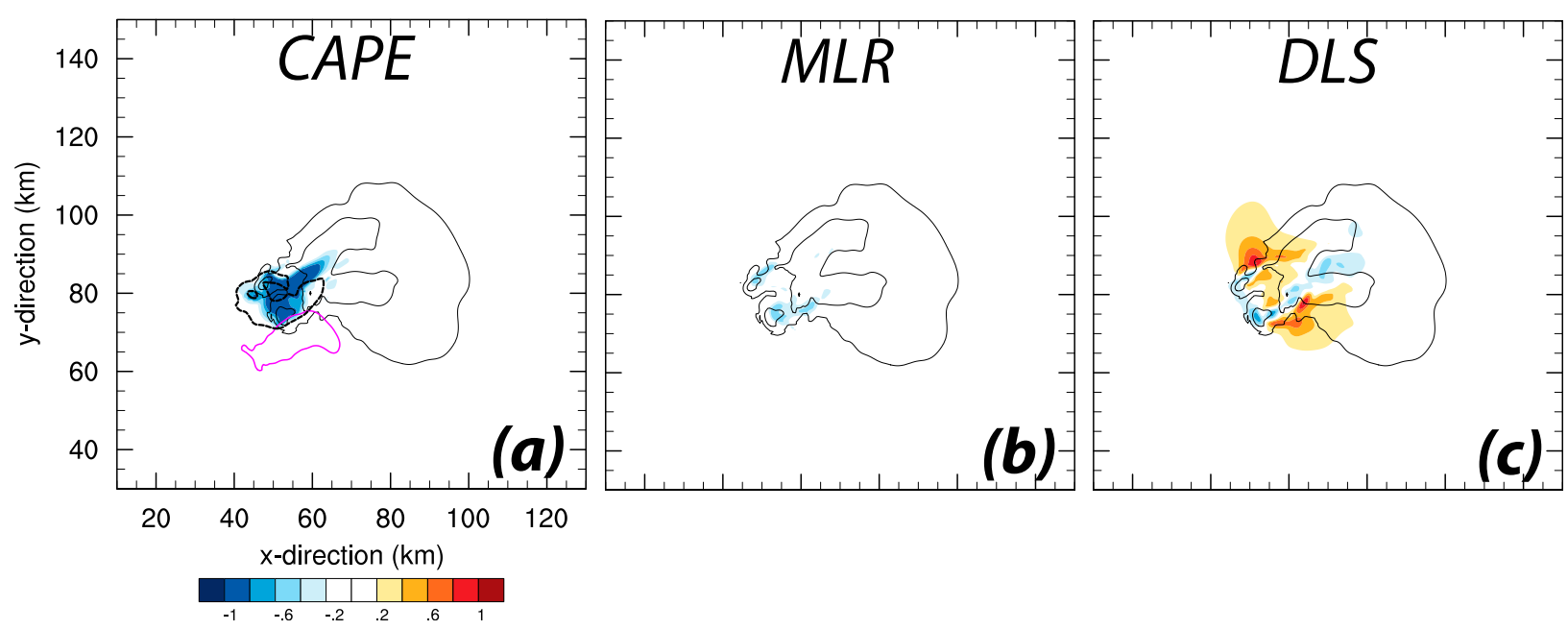

FIG. 4. Analyses of (a) (ML) CAPE, (b) MLR, and (c) DLS, as normalized differences relative to their respective environmental values, from the 19 May 2013 simulation at $t=50 \mathrm{~min}$. Thin black contour overlays are of simulated radar reflectivity factor (30,50 dBZ). Dashed black contour in (a) is the $-1{ }^{\circ} \mathrm{C}$ perturbation potential temperature at $z=250 \mathrm{~m}$, and magenta contour in (a) is the 50 - $\mathrm{dB} Z$ simulated radar reflectivity factor at $t=35 \mathrm{~min}$. Only a portion of the domain is shown.

exhibits the expected saturated, moist adiabatic profile of a locally stabilized atmosphere (Fig. 5a). By $t=55 \mathrm{~min}$, the atmospheric profile at that same location has undergone dramatic cooling and drying, especially above the boundary layer (Fig. 5b); as Fig. $3 b$ illustrates, the updraft core and storm moved $\sim 7.5 \mathrm{~km}$ toward the northeast during this 5 -min interval. Subsequent movement and evolution of the storm and its expanding cold pool (Fig. 3c) allowed the local profile to undergo further destabilization, so that by $t=70 \mathrm{~min}$, the profile has recovered most of its preconvective structure above the boundary layer and cold pool (Fig. 5c); recovery of the boundary layer structure occurs by $t=90 \mathrm{~min}$ (not shown). We note that thermodynamic-profile recovery at locations affected by the other updraft core was even more rapid, because these locations were occupied by the cold pool for only a brief time.

An evaluation of the thermodynamic energy equation within CM1 helps us better understand the processes responsible for this local evolution. Symbolically, the equation can be written as

$$
\begin{aligned}
\frac{\partial \theta^{\prime}}{\partial t}= & - \text { HADV }- \text { VADV + DIAB } \\
& +(\text { TURB }+ \text { NEWT + DIFF + DISS }),
\end{aligned}
$$

where $\theta^{\prime}$ is the perturbation potential temperature, defined as the difference between the total potential
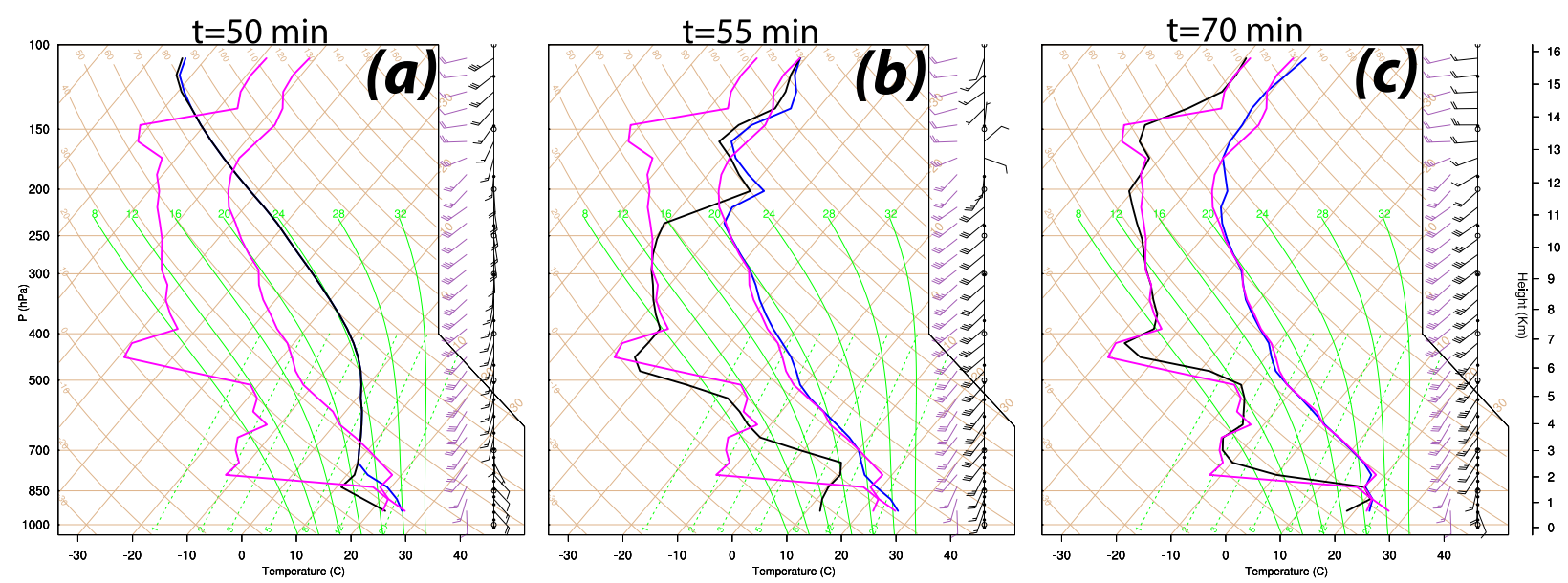

FIG. 5. Skew $T-\log p$ diagram of model soundings at grid point $(x=51, y=86 \mathrm{~km})$ from the 19 May 2013 simulation: (a) $t=50$, (b) $t=55$, and (c) $t=70 \mathrm{~min}$. One full (half) barb equates to $10(5) \mathrm{m} \mathrm{s}^{-1}$. The magenta lines and barbs show the initial/environmental profile. 

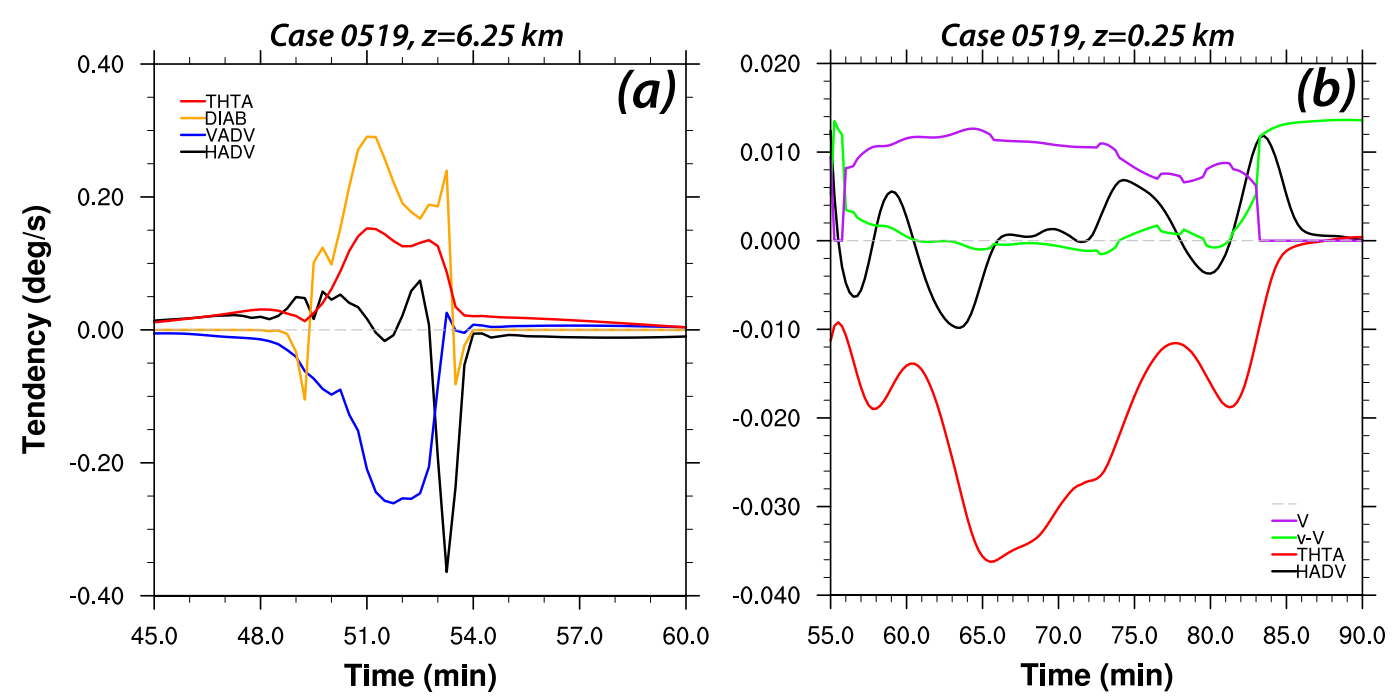

FIG. 6. (a) Time series of perturbation potential temperature (THTA; K, $\times 10^{-2}$ ) and the thermodynamic energy equation tendency terms (see text): HADV, VADV, DIAB $\left(\mathrm{K} \mathrm{s}^{-1}\right)$ at a constant height $(z=6.25 \mathrm{~km})$ and grid point $(x=51, y=86 \mathrm{~km})$. (b) Time series of density current speed $\left(V ; \mathrm{m} \mathrm{s}^{-1}, \times 10^{-3}\right)$, and THTA, HADV, and $v-V\left(\mathrm{~m} \mathrm{~s}^{-1}, \times 10^{-3}\right)$ at $z=0.25 \mathrm{~km}$, and $(x=51, y=86 \mathrm{~km})$. These are from the 19 May 2013 simulation.

temperature $\theta$ and the vertically dependent base-state potential temperature; HADV and VADV are horizontal and vertical advections, respectively, of the total potential temperature by the total wind; DIAB is the latent heating from microphysical phase changes; TURB is the subgrid turbulent mixing of total potential temperature; NEWT is a Newtonian relaxation term; DIFF encompasses artificial diffusion; and DISS is the heating that occurs when kinetic energy is dissipated (Bryan and Fritsch 2002; see also Bryan 2016). The terms in Eq. (1) were determined at 15-s intervals. In our simulations, the last four (i.e., parenthetical) terms are relatively small, and thus they are omitted from the analysis that follows.

A time series of HADV, VADV, DIAB, and $\theta^{\prime}$ at gridpoint location $(x=51, y=86 \mathrm{~km})$ and constant height $(z=6.25 \mathrm{~km})$ reveal at $t=48 \mathrm{~min}$ the expected negative contribution of VADV representing adiabatic cooling within the updraft, and the expected positive contribution of DIAB representing latent heating (Fig. 6a). The stabilization shown in the $t=50 \mathrm{~min}$ sounding (Fig. 5a) can be attributed to such diabatic heating, as well as to HADV, which represents the horizontal transport of previously generated heat. Beginning at $t=53 \mathrm{~min}$, substantial cooling driven by HADV and subsequently by DIAB leads to the recovery that is realized in the $t=55 \mathrm{~min}$ sounding (Fig. 5b). Analyses of the thermodynamic tendencies at other heights show a consistent evolution, and highlight the fact that the local time scales of the respective stabilization and recovery processes are on the order of minutes.
This rapid cooling from horizontal advection might seem surprising, given that in deep continental convection, initial destabilization as well as recovery is generally considered to involve synoptic-scale processes, and thus be slow relative to the stabilization (e.g., Emanuel 1994). For example, let us simplify Eq. (1) as

$$
\frac{\Theta}{\tau} \approx-U \frac{\Delta \theta}{\Delta x}
$$

where $\Theta$ is the potential temperature change that constitutes destabilization from an initially stabilized atmosphere; $\tau$ is the time interval over which such recovery takes place; $U$ is the advecting wind, assumed to be constant; and $\Delta \theta / \Delta x$ is the horizontal potential temperature gradient, assumed to depend only on $x$. Consulting the $t=50 \mathrm{~min}$ sounding in Fig. 5a, we see that at $z \sim 6 \mathrm{~km}$ (the $500-\mathrm{hPa}$ level), the difference between the stabilized and recovered potential temperature change is approximately $-10^{\circ} \mathrm{C}(=\Theta)$. If we let $U=25 \mathrm{~m} \mathrm{~s}^{-1}$, representative of a midtropospheric synoptic-scale jet, and assign to $\Delta \theta / \Delta x$ a constant value of $1^{\circ} \mathrm{C}(100 \mathrm{~km})^{-1}$, which results in a strong but not atypical synoptic-scale advection, we find that $\tau$ is $\sim 0.5$ day. Synoptic-scale (e.g., quasigeostrophic) vertical motions and associated layer lifting [as represented in Eq. (1) by VADV] would reduce this destabilization time, but it still would be many hours rather than minutes.

Now let us consider the advection that specifically involves the potential temperature field within a convective updraft, which we model as 


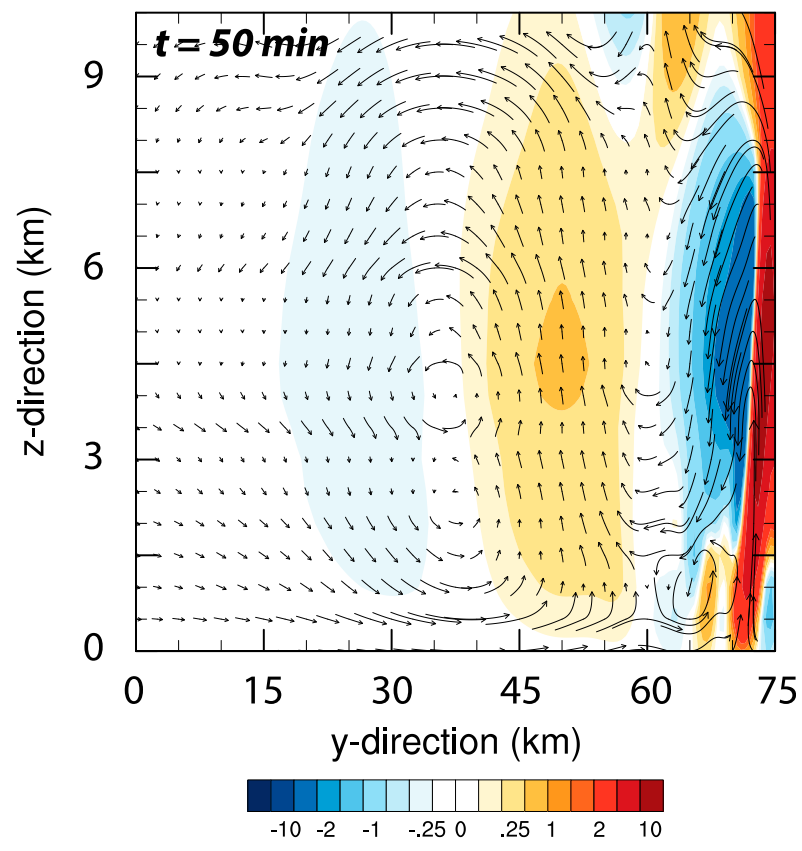

FIG. 7. Vertical cross section of the vertical velocity $\left(\mathrm{m} \mathrm{s}^{-1}\right.$; color fill) and perturbation wind $(v, w)$ vectors in the $x=51-\mathrm{km}$ plane, from the 19 May 2013 simulation at $t=50 \mathrm{~min}$. Only a portion $(0 \leq$ $y \leq 75 \mathrm{~km}, 0 \leq z \leq 10 \mathrm{~km}$ ) of the domain is shown.

$$
\theta(x)=\left\{\begin{array}{ll}
A \sin \left(\frac{\pi}{D} x\right), & 0 \leq x<D \\
0, & x \geq D
\end{array} .\right.
$$

Here, $A$ is the maximum temperature excess within an updraft core, and $D$ is the updraft core diameter. Based on Fig. 3a, we let $A=10^{\circ} \mathrm{C}, D=5 \mathrm{~km}$, and then evaluate Eq. (2) using $\partial \theta / \partial x=|A(\pi / D) \cos (\pi x / D)|$ at its maximum $x$ (i.e., where $x=0$ or $D$ ). Consistent with Fig. 6c, we find that $\tau$ is $\sim 1 \mathrm{~min}$.

The interpretation of this simple exercise, and of the results shown in Figs. 4 and 6a, is that the processes that force the convective stabilization and recovery above the boundary layer are largely Lagrangian and thus move with the storm. Accordingly, the stabilization and recovery time scale is essentially an advective time scale governed by the updraft length scale and a (midtropospheric) horizontal velocity scale.

This time scale excludes elimination of the cold pool and its inhibition of surface-based convection. Because our idealized simulations lack radiative and surface fluxes, the near-surface local tendency in $\theta^{\prime}$ is dominated by advections (Fig. 6b). At a fixed location (such as $x=51$, $y=86 \mathrm{~km}$ ), the advective velocity is largely a combination of the near-surface environmental winds (in this case, comprising mostly the $v$ component; Fig. 5) and the winds induced by the cold pool. Following Bryan and
Parker (2010), we approximate such winds with a density current speed $V$, where $V^{2}=-2 \int B d z, B$ is total buoyancy (e.g., Weisman and Rotunno 2000), and the integration is taken over the surface-based depth that terminates where $B$ first equals zero; $V$ is assumed to be isotropic. Figure $6 \mathrm{~b}$ reveals that the elimination of the negative $\theta^{\prime}$ of the cold pool corresponds to an exceedance of $v$ over $V$; in essence, the local advection after $t \sim 83 \mathrm{~min}$ is of environmental air rather than that of the cold pool; $V$ and $\theta^{\prime}$ are, of course, interrelated through the vertically integrated buoyancy, which will weaken through subgrid-scale mixing (TURB) and otherwise evolve as its diabatic source (the storm) moves and also dissipates. An inclusion of radiative and surface fluxes would further complicate the time scale of cold pool elimination.

The simple time scale following Eqs. (2)-(3) also excludes the effect of adiabatic heating owing to weak downdrafts outside of the main updraft. This "compensating subsidence" (see the discussion by Mapes 1997), which is governed by VADV in Eq. (1), occurs in gravity wave disturbances (e.g., Bretherton and Smolarkiewicz 1989; Nicholls et al. 1991; Mapes 1993); Mapes (1993) has termed these disturbances "buoyancy bores," because they exhibit gravity wave dispersion, but do not oscillate. As demonstrated in Fig. 7, the structure of the gravity waves in this simulation is initially similar to the time-varying $n=1$ mode described by the analytical solutions of Nicholls et al. (1991). Specifically, the $n=1$ mode is characterized by a horizontally propagating column of deep-tropospheric descent, followed by a layer of warming, confined above and below by horizontal outflow and inflow (relative to the primary updraft and bore generator), and then followed by a column of deep-tropospheric ascent [see Fig. 10 in Nicholls et al. (1991)]. In the absence of a background wind, this propagating disturbance is symmetrical about its diabatic-heating source. Mapes (1993), Lane and Reeder (2001), Fovell (2002), AdamsSelin and Johnson (2013), and others have focused on the downstream propagation of these disturbances (or propagation in the direction of the storm motion) and their effect on the prestorm environment. Our interest here is on the upstream propagation, and the effect of such propagation on local convective stabilization and recovery.

The horizontal phase speed of the disturbance is

$$
c=\frac{N H}{n \pi},
$$

where $H$ is the depth of the troposphere, $n$ is the vertical mode over this depth, and $N$ is the Brunt-Väisällä 


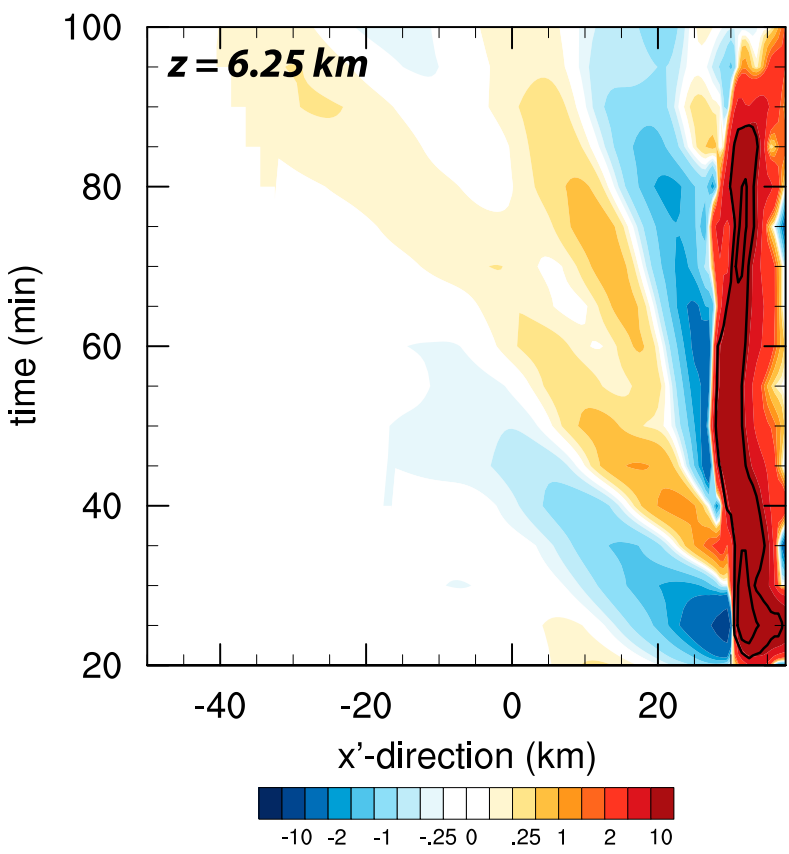

FIG. 8. Hovmöller diagram of vertical velocity $\left(\mathrm{m} \mathrm{s}^{-1}\right.$; color fill), and diabatic heating contours $\left(0.05,0.1 \mathrm{~K} \mathrm{~s}^{-1}\right)$, at $y=86$ and $z=$ $6.25 \mathrm{~km}$, for the 19 May 2013 simulation. Before processing the vertical velocity and diabatic heating data, the $x$ and $y$ axes are rotated so that the storm motion is approximately along the $x$ axis. Only a portion $\left(-50 \leq x^{\prime} \leq 37.5 \mathrm{~km}, 20 \leq t \leq 100 \mathrm{~min}\right)$ of the timespace domain is shown. In the Hovmöller diagram, the $x$ coordinate is rotated such that $x^{\prime}=x+0.4 t$.

frequency, represented here as in Adams-Selin and Johnson (2013) as

$$
N^{2}=\frac{g}{\theta_{v}} \frac{d \theta_{v}}{d z}
$$

where $\theta_{v}$ is the virtual potential temperature. Implicit in Eq. (4) are assumptions of hydrostatic balance, a restriction to a $2 \mathrm{D}(x-z)$ plane, and a rigid tropopause at a height $z=H$. In the 19 May 2013 environmental sounding, $H=12.5 \mathrm{~km}$, and the Brunt-Väisällä frequency averaged about $H / 2$ is $\bar{N}=0.009 \mathrm{~s}^{-1}$. From Eq. (4), $c=38.1 \mathrm{~m} \mathrm{~s}^{-1}$ for $n=1$. Accounting for the zonal component of the mean tropospheric wind $(\bar{u}=$ $15.8 \mathrm{~m} \mathrm{~s}^{-1}$ ), and additionally for the zonal component of the storm motion $\left(u_{s}=8.3 \mathrm{~m} \mathrm{~s}^{-1}\right)$ and, therefore, of the motion of the heating source, we find that the Dopplershifted phase speeds are $\bar{u}+u_{s}-c=-14.0 \mathrm{~m} \mathrm{~s}^{-1}$ and $\bar{u}+u_{s}+c=62.2 \mathrm{~m} \mathrm{~s}^{-1}$, for westward (i.e., upstream) and eastward (i.e., downstream) propagations, respectively. A comparable westward propagation speed of $-13.0 \mathrm{~m} \mathrm{~s}^{-1}$ is estimated from the slope of the initial vertical-velocity phase lines in a Hovmöller diagram (prior to coordinate axes rotation; Fig. 8). The Hovmöller diagram also reveals a change in the phase-line slope, reflective of a change in the vertical mode due to the development of a cold pool (see section 3c), and reveals a gradual demise in the diabatic heating (and storm itself) and thus in the gravity wave generation. The demise in wave generation, coupled to a relatively slow westward propagation, resulted in a limited impact of this wave-associated heating on the convective stabilization and recovery.

\section{b. 23 May and 30 May 2013 supercells}

To determine the extent to which the convective stabilization and recovery associated with the 19 May 2013 supercell can be generalized, we now consider two additional cases from MPEX. On 23 May 2013, the MPEX upsonde teams sampled a pair of supercells, one of which produced three brief tornadoes near Floydada, Texas, and the other produced an EF-1 tornado near Spur, Texas (Fig. 1b). The supercell wake sounding was collected approximately 9 min after this EF-1 tornado occurrence. On 30 May 2013, the MPEX upsonde teams sampled a severe supercell that initiated west of Chickasha, Oklahoma. The wake sounding for this case was released at 2002 UTC, roughly $45 \mathrm{~min}$ after local storm passage (Fig. 1c).

Figures $9 \mathrm{a}$ and $9 \mathrm{~b}$ provide a comparison between the preconvective and supercell-wake environments on 23 May 2013. The wake sounding exhibits a temperature structure that, over the layer between $\sim 900$ and $450 \mathrm{hPa}$, is also qualitatively and quantitatively similar to that of preconvective sounding. Indeed, the $700-500-\mathrm{hPa}$ MLR is nearly the same in the two soundings (Table 2). The significant reductions in wake $\mathrm{SBCAPE}_{475}$ and MLCAPE $_{475}$ are therefore attributable to the low-level temperature inversion of the cold pool, and its associated boundary layer drying.

The longer lag between the local storm passage and sounding release on 30 May 2013 would suggest more time for local convective recovery, and therefore suggest even more similarity between the preconvective and supercell-wake environments. The wake sounding shows some enhancement of $\sim 550-\mathrm{hPa}$ warming and drying that was also evident in the preconvective sounding (Figs. 9c,d). This reduced the 700-500-hPa MLR in the wake (Table 2). A low-level inversion indicative of a cold pool is also apparent, as is a shallow surface-based layer within the cold pool, suggestive of warming and moistening by surface fluxes. In both cases, slight DLS enhancements in the wake soundings are due to presumably outflow winds (as well as to midlevel mesocyclonic circulations, as sampled by the sonde during its drift relative to a moving storm; Fig. 1). 

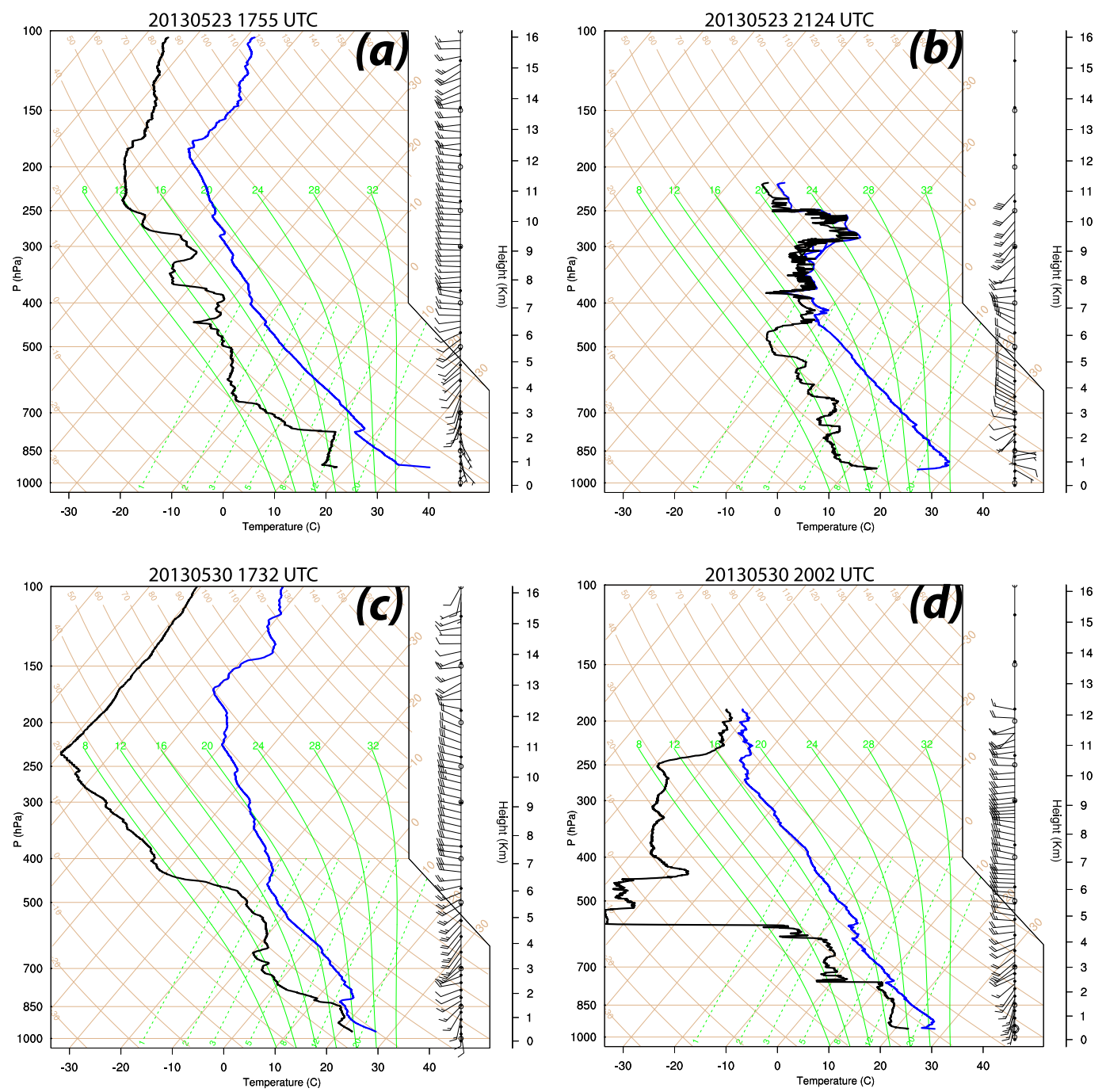

FIG. 9. As in Fig. 2, but at (a) 1755 and (b) 2124 UTC 23 May 2013, and at (c) 1732 and (d) 2002 UTC 30 May 2013.

As done in section 3a, we again consult numerical simulations (see Fig. S2 in the online supplemental material) to aid in the interpretation of these observations. Figures $10 \mathrm{a}$ and $10 \mathrm{c}$ provide a spatial context to CAPE modifications due to the 23 May and 30 May 2013 simulated supercells at $t=60$ and $t=95 \mathrm{~min}$, respectively. The largest CAPE reductions are again within the area encompassed by the cold pool. Smaller CAPE reductions are found outside of the cold pool and cloud boundary, and are due largely to the adiabatic heating associated with gravity waves. This is particularly true in the 23 May 2013 case, owing to the relatively more convective heating with a supercell pair. MLR reductions in these two cases are similar to those found in the 19 May 2013 case, specifically, within updraft regions (Figs. 10b,d). The DLS modifications are again found mostly on the flanks of the mesocyclonic circulations, with minor modifications attributed to the gravity waves (Figs. 10c,e). This supports our previous statement that the supercell-induced stabilizations are indeed local ( $\sim$ cold-pool radius), and have little appreciable remnants that coincide with the history of the supercell.

Further consistency in the stabilization-recovery evolution is shown by local time sequences of model soundings at fixed gridpoint locations for 23 May $2013(x=66.5$, $y=79.0 \mathrm{~km})$ and 30 May $2013(x=56.5, y=90.5 \mathrm{~km})$ (Figs. 11a,c). Stabilization by way of latent heating within an updraft core is indicated in both cases, with the depths of the moist ascent dependent upon the size and vertical erectness of the updraft. Local recovery in the 23 May 2013 case is delayed by the slow motion and somewhat more complicated structure of the supercell pair, but is largely achieved above the boundary layer 

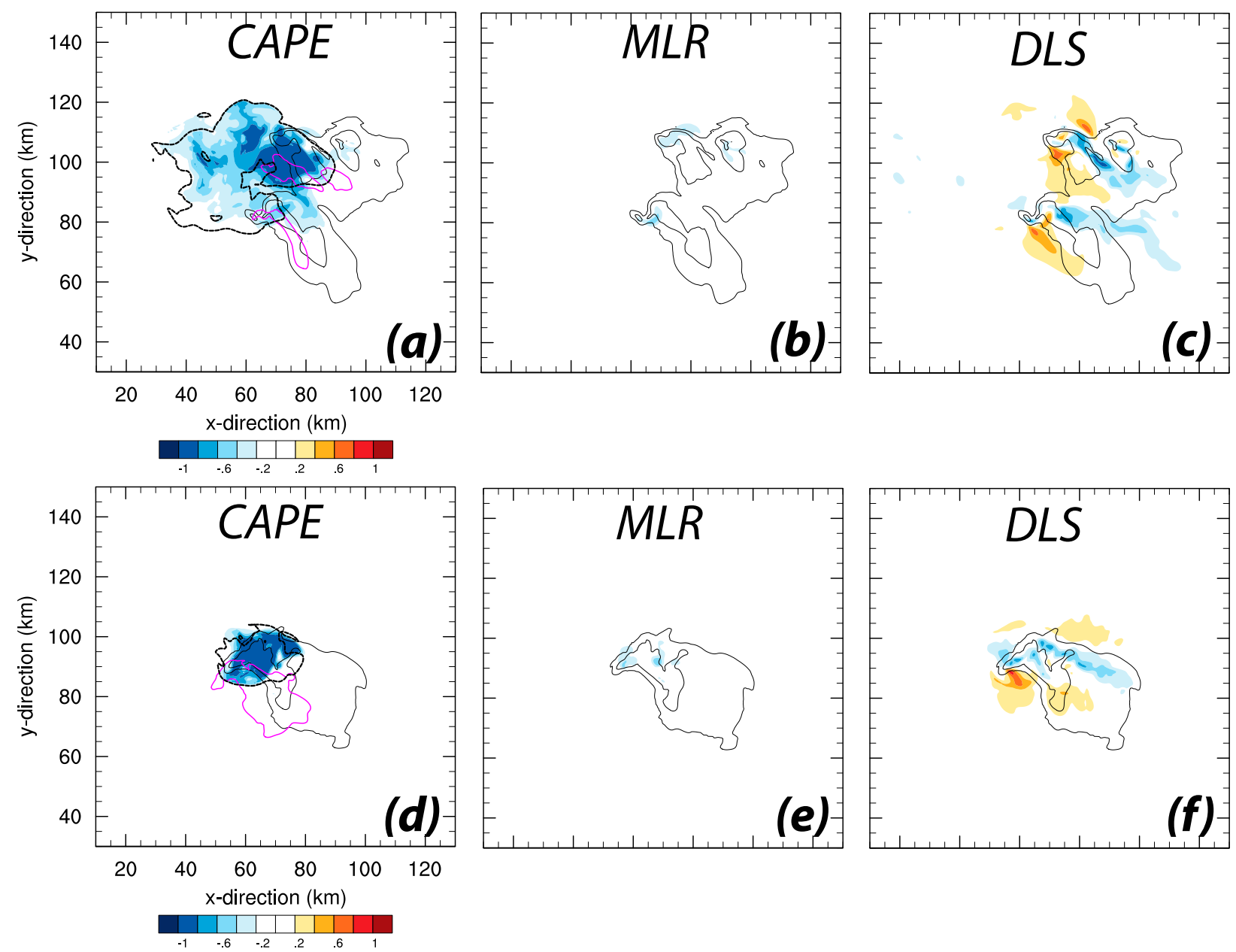

FIG. 10. As in Fig. 4, but for (a)-(c) the 23 May 2013 simulation at $t=95$ min and (d)-(f) the 30 May 2013 simulation at $t=60$ min. Magenta contour is $50-\mathrm{dBZ}$ simulated radar reflectivity factor at $t=80 \mathrm{~min}$ in (a), and at $t=45 \mathrm{~min}$ in (d).

by $t=120 \mathrm{~min}$ (Fig. 11b). Local recovery in the 30 May 2013 case resembles that of 19 May 2013, and is largely achieved above the boundary layer by $t=70 \mathrm{~min}$ (Fig. 11d).

The processes underlying such evolution are summarized by time series of the HADV, VADV, and DIAB terms of Eq. (1) evaluated in at a constant height $(z=$ $6.25 \mathrm{~km}$ ) and at the same gridpoint locations (Fig. 12). For the 23 May 2013 case, an extended interval of positive DIAB provides for net heating when supplemented by positive HADV (Fig. 12a). In the Eulerian framework of this analysis, an extended interval relates to a broad and/or slowly moving updraft, as can be deduced from the VADV signal (and confirmed by Fig. S2 in the online supplemental material). Positive contributions from VADV at $t=92$ and $t=118 \mathrm{~min}$ are associated with downdrafts on the updraft flanks. Finally, the negative contributions of HADV beginning $t \sim 114 \mathrm{~min}$ simply represent the approach of the trailing edge of the updraft (and flanking downdraft) and thus trailing temperature gradient. The local time series for the 30 May 2013 case is more complicated because of a more complicated and evolving updraft (Fig. 12b), but the essence of the processes is the same as for the 23 May 2013 and 19 May 2013 cases.

Building on the idea introduced in section $3 \mathrm{a}$, local horizontal advection in the storm wake depends on the gradients of perturbation temperature induced by latent heating and adiabatic compression (and expansion), as acted upon by the environmental winds and the wind perturbation induced by gravity waves. Absence of the environmental winds implies an absence of horizontal advection, and thus of a robust process that can locally mitigate the heat generated diabatically and adiabatically. This explains the semipermanent increase in buoyancy by buoyancy bores in quiescent atmospheres, as considered by Bretherton and Smolarkiewicz (1989), Nicholls et al. (1991), and Mapes (1993). 

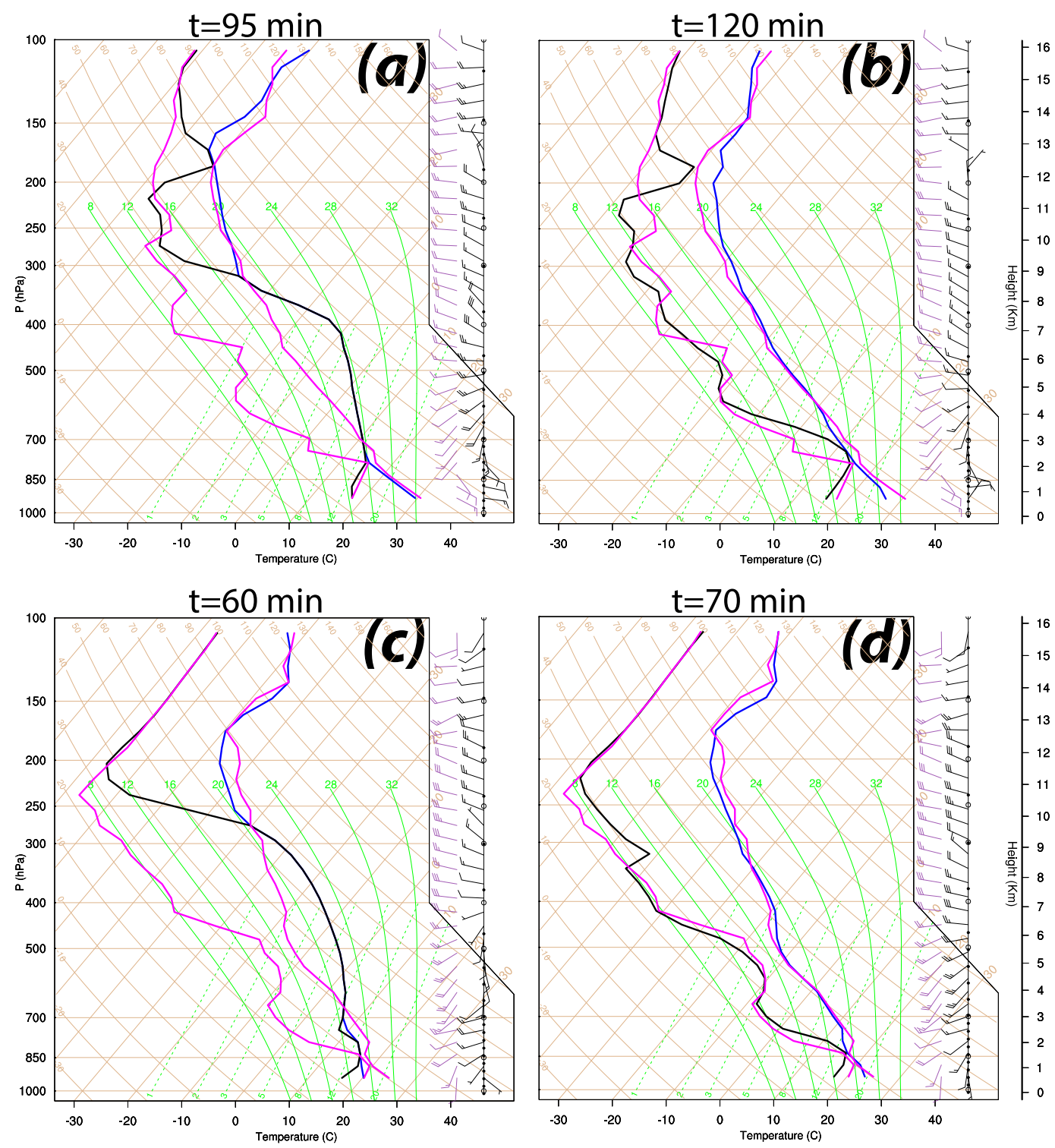

FIG. 11. As in Fig. 5, but for the 23 May 2013 simulation at (a) $t=95$ and (b) $t=120$ min at grid point $(x=66.5, y=$ $79.0 \mathrm{~km}$ ), and for the 30 May 2013 simulation at (c) $t=60$ and (d) $t=70 \mathrm{~min}$ at grid point $(x=56.5, y=90.5 \mathrm{~km})$.

There is additional interplay between the speed of the environmental winds, and the intrinsic phase speed of the gravity wave: weaker winds imply a faster upstream (Doppler shifted) phase speed, and thus a farther reach of the wave and adiabatic heating. In fact, the impact of gravity waves on convective recovery appears to be more pronounced in the far (upstream) field in weakerwind cases. Experiments conducted in section $3 \mathrm{c}$ will address this.

\section{c. Two idealized cases}

In this final subsection, we enlist idealized wind profiles and the analytic sounding of Weisman and
Klemp (1982) to generate simulations of convective storms that can be considered archetypal, and thus that are relatively well documented in the literature. The first experiment (hereafter WKSC) uses a "quarter circle" hodograph with a $7 \mathrm{~m} \mathrm{~s}^{-1}$ radius over the lowest 2-km depth, thus supporting the evolution of a splitting supercell (e.g., Weisman and Rotunno 2000) (see Fig. S3a in the online supplemental material). The second experiment (hereafter WKSL) uses a "straight line" hodograph with a change of $20 \mathrm{~m} \mathrm{~s}^{-1}$ in the zonal wind speed over the lowest $2.5-\mathrm{km}$ depth. This supports the evolution of a mesoscale convective system (MCS) in the form of a bow-echo squall line 

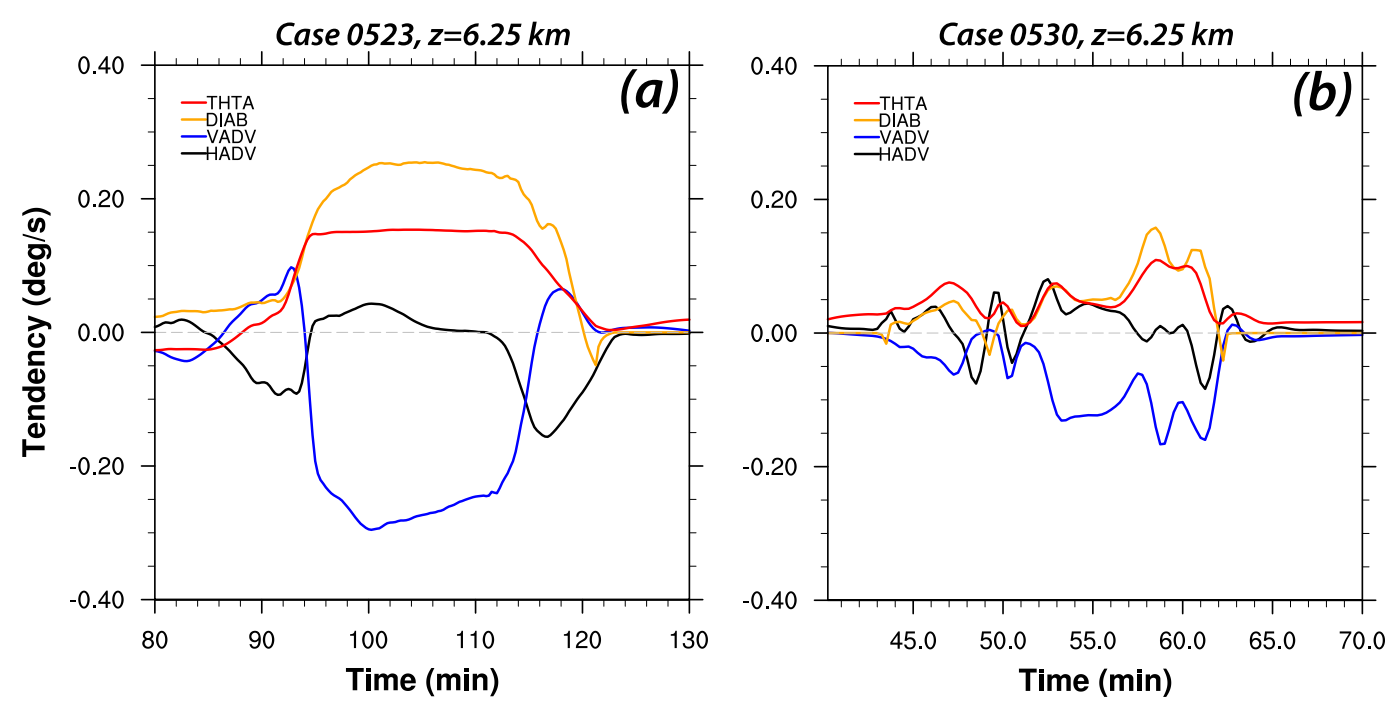

FIG. 12. As in Fig. 6a, but for (a) the 23 May 2013 simulation at grid point ( $x=66.5, y=79.0 \mathrm{~km}$ ) and (b) for the 30 May 2013 simulation at grid point $(x=56.5, y=90.5 \mathrm{~km})$.

(e.g., Weisman and Trapp 2003) (see Fig. S3b in the online supplemental material), and thus allows us to compare and contrast the stabilization and recovery associated with a different, and larger mode of organized convection.

Compared to the three MPEX cases shown previously, the idealized environment of the WKSC simulation supports a longer-lived splitting supercell, with a deeper and (spatially) larger cold pool. Although the basic convective stabilization and recovery processes are the same in this case as in the MPEX cases, these temporal and spatial attributes of the WKSC case imply a comparatively slower local recovery. Consider a sequence of model soundings at grid point $(x=69$, $y=81 \mathrm{~km}$ ). Following the passage of the (right moving) updraft core and the associated convective stabilization (Fig. 13a), the local atmospheric profile undergoes dramatic cooling and drying, especially above the boundary layer (Fig. 13b). However, the apparently persistent adiabatic heating (and drying) aloft combined with a deep and strong pool precludes full recovery of the preconvective atmospheric structure even by $t=120 \mathrm{~min}$ (Fig. 13c).

Such persistence is confirmed by a Hovmöller diagram, which shows relatively wider and longer-duration wave-associated downdrafts (see Figs. 8 and 14a). Based on the analytic solutions of Nicholls et al. (1991), the wider wave-associated drafts owe to the wider area (strictly, the half width) of diabatic heating (Fig. 14a). The wave duration relates in part to the duration of pulses in diabatic heating, although ultimately is limited by a Rossby deformation radius $(=c / f)$, which here is the distance over which the disturbances can propagate before undergoing significant attenuation (e.g., Mapes 1993).

Gravity wave-associated heating aloft is even more pronounced in the WKSL simulation, as is also demonstrated through a model-sounding sequence at a representative grid point $(x=145, y=180 \mathrm{~km})$. Saturated ascent through a tilted updraft within the leading convection is suggested at $t=120 \mathrm{~min}$ (Fig. 13d). Soon thereafter, horizontal advection of environmental air aids local cooling and destabilization, albeit only over the lowest half of the troposphere and above the cold pool (Fig. 13e). Despite the trend indicated in Figs. 13e and 13f, the preconvective atmospheric structure is still not recovered at $t=300 \mathrm{~min}$, which is $3 \mathrm{~h}$ after the convective stabilization (Fig. 13f).

A key impedance to convective recovery is again revealed by a Hovmöller diagram (Fig. 14b), which is taken through the center of the MCS. It indicates a gravity wave propagation that is initially similar to that of the supercell, yet with a phase-line estimated speed of $-25.1 \mathrm{~m} \mathrm{~s}^{-1}$ (and calculated Doppler-shifted phase speed of $\left.\bar{u}+u_{s}-c=-20.0 \mathrm{~m} \mathrm{~s}^{-1}\right)$, which is faster than that of the supercell (phase line estimate of $9.9 \mathrm{~m} \mathrm{~s}^{-1}$, calculation of $\bar{u}+u_{s}-c=-10.4 \mathrm{~m} \mathrm{~s}^{-1}$ ). As alluded to in section $3 \mathrm{~b}$, the faster upstream phase speed in the WKSL simulation is enabled by the relatively weak environmental winds $\left(\bar{u}=12.5 \mathrm{~m} \mathrm{~s}^{-1}\right)$, and implies a farther reach of the wave-associated heating. Accordingly, an MCS environment with an identical thermodynamic profile but stronger environmental winds (and presumably, therefore, a faster storm motion) would lead to a slower Doppler-shifted phase speed and thus more limited heating aloft. 

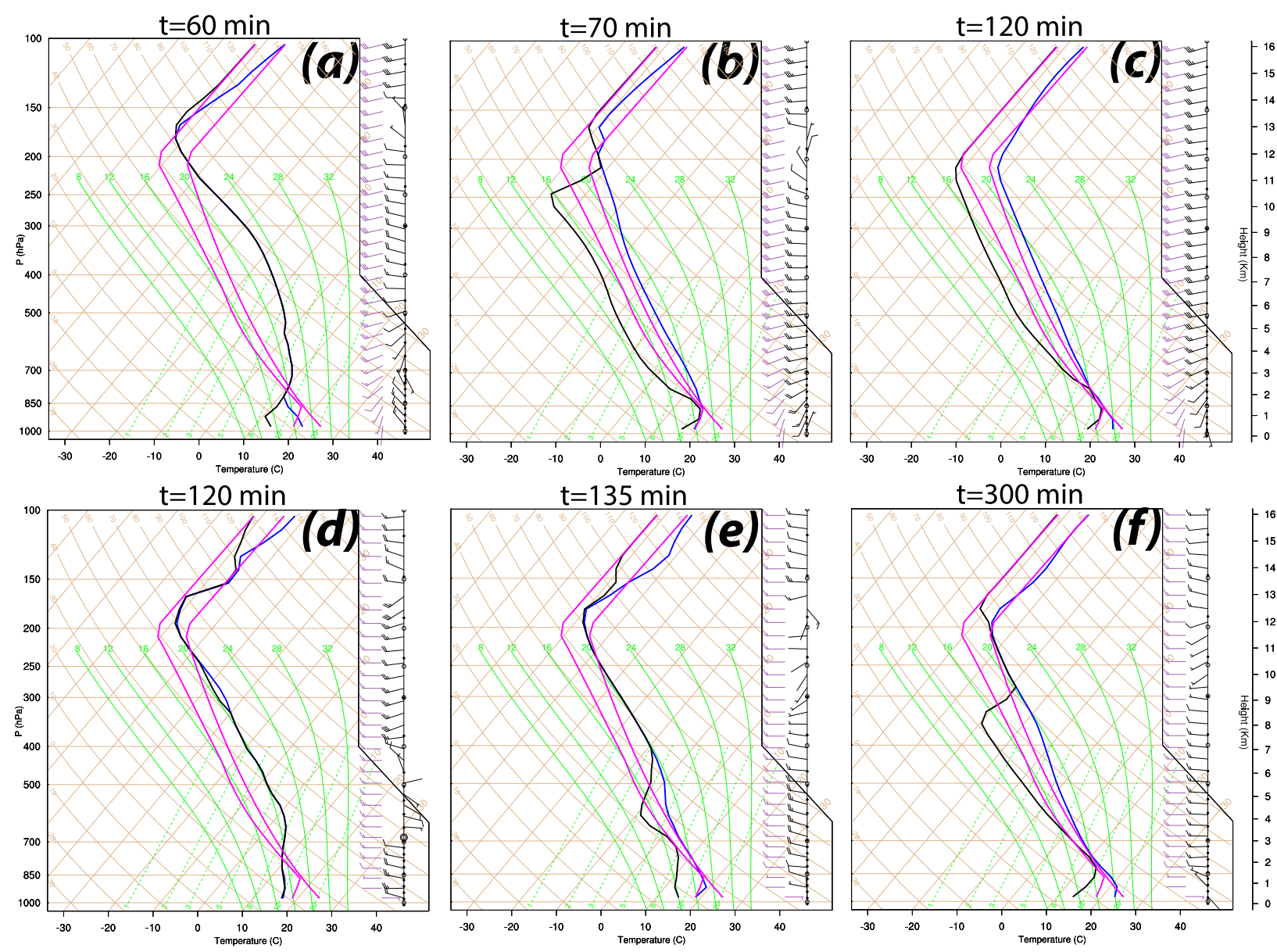

FIG. 13. As in Fig. 5, but for the WKSC simulation, at grid point $(x=68, y=100 \mathrm{~km}$ ) at (a) $t=60$, (b) $t=70$, and (c) $t=120 \mathrm{~min}$, and for the WKSL simulation, at grid point $(x=145, y=180 \mathrm{~km})$ at (d) $t=120$, (e) $t=135$, and (f) $t=300 \mathrm{~min}$.

In the Hovmöller diagram we note that the slopes of the phase lines change after $t \sim 100 \mathrm{~min}$ (Fig. 14b), which is roughly the time that the cold pool has a temperature deficit that exceeds several degrees Celsius, and a depth that exceeds that of the preconvective boundary layer. The implication of such a significant cold pool is that the diabatic heating profile now has a cooling component over roughly the lowest two kilometers above the ground, and a warming component aloft. And, the atmospheric response to such a heating profile is an $n=2$ gravity wave (Nicholls et al. 1991; Mapes 1993), which per Eq. (4) has an intrinsic phase speed that is one-half that of the $n=1$ wave (and which is indeed consistent with a phase-line estimated speed of $-12.7 \mathrm{~m} \mathrm{~s}^{-1}$ ). The $n=2$ wave comprises a circulation cell with the $n=1$ sense of rotation, atop a circulation cell with an opposite sense of rotation. In terms of adiabatic processes, the $n=2$ wave results in adiabatic heating aloft, and adiabatic cooling below. Thus, the slower-moving, wave-induced adiabatic warming aloft and adiabatic cooling below acts to maintain the local convective stabilization nearer to the convective line.

\section{Conclusions}

The convective effects considered here, which are the "overturning" or stabilizations, are largely Lagrangian: they move with the supercell storm. The local or Eulerian "recovery" of the temperature and moisture (and momentum) profiles to a preconvective state is largely due to advection (as well as radiative heating, which was not included in the idealized numerical modeling). Note that the advection here is associated with storm-scale rather than synoptic-scale gradients. Thus, the recovery rate is approximately tens of minutes instead of the $\sim 10 \mathrm{~h}$ required to initially generate the unstable, preconvective stratifications.

This rapid recovery excludes the atmosphere occupied by the cold pool. The cold pool can persist on relatively long time and large spatial scales. The persistence and scales depend on the cold-pool characteristics 

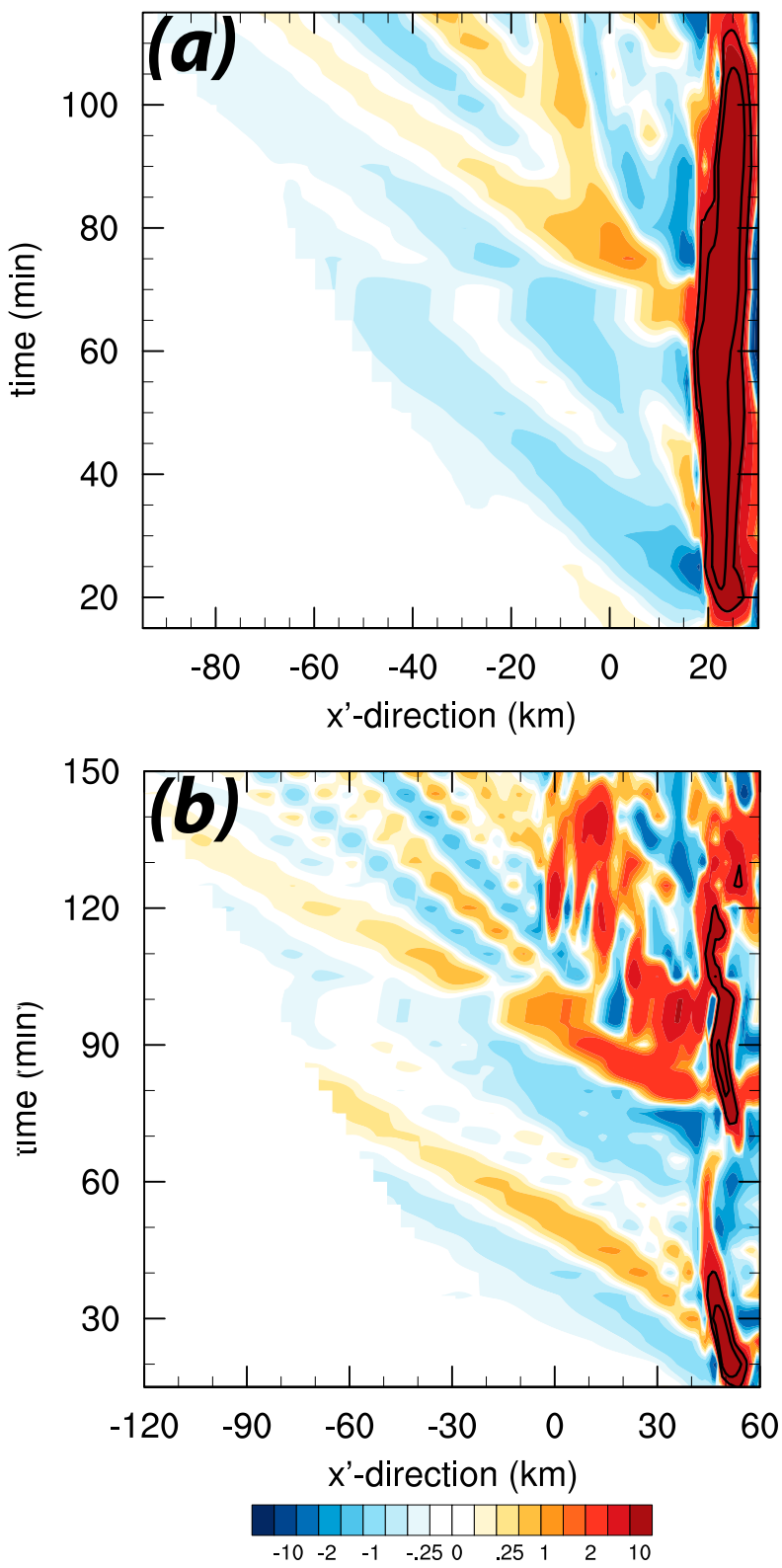

FIG. 14. As in Fig. 8, but at $z=6.25 \mathrm{~km}$ for (a) the WKSC simulation at $y=190 \mathrm{~km}$ over domain $\left(-95 \leq x^{\prime} \leq 30 \mathrm{~km}, 15 \leq t \leq\right.$ $115 \mathrm{~min}$ ), and (b) the WKSL simulation at $y=180 \mathrm{~km}$ over domain $\left(-120 \leq x^{\prime} \leq 60 \mathrm{~km}, 15 \leq t \leq 150 \mathrm{~min}\right)$. In the Hovmöller diagram, the $x$ coordinate is rotated such that $x^{\prime}=x+0.79 t$.

(depth, buoyancy deficit), as well as implicitly on the storm characteristics, environmental wind and thermodynamics, land surface and associated fluxes, and radiative fluxes (e.g., Del Genio et al. 2012). Our future work will help us quantify these individual effects, but we can conclude in general that a persistent cold pool means a reduced likelihood for the initiation of boundary layerbased deep convection within the area occupied by the cold pool; however, convection that is "elevated" above the cold pool is possible.

The adiabatic heating in gravity wave disturbances (buoyancy bores) that propagate upstream relative to the moving convective storm also impedes recovery, and thus also reduces the likelihood of convection initiation in the supercell wake. The persistency and intensity of the wave effects depend on the persistency and intensity of the diabatic heating; in the idealized model approach used here, these ultimately relate back to environmental thermodynamics and wind, and also on the parameterized microphysical processes. The extent of the upstream wave propagation also depends on the environmental thermodynamics (intrinsic phase speed) and wind (Doppler shift). Because the intrinsic phase speed tends to be large, the magnitude of the environmental wind has an important influence. Specifically, weaker winds aloft allow for faster (and farther) upstream propagation, as was shown in the example of the idealized MCS.

One key implication of this work is that the initiation and evolution of deep convective clouds in NWP models, especially those with "convection allowing" resolution, will depend on the proper model representation of convectively generated cold pools and their effects (e.g., Stensrud et al. 1999). By "effects" we are referring specifically to the contribution of the cold pool to a surface-based inhibition of convection, rather than to the contribution of the cold pool to convection initiation through parcel lifting at its leading edge. Such NWP accuracy will also require accuracy in the representation of gravity waves, which in turn requires accuracy in the magnitude, spatial structure, and temporal evolution of the diabatic heating, especially that due to microphysical latent heating.

Our future work will include a quantification of how the misrepresentation of these processes impacts shortterm mesoscale predictability. It will also include an exploration of the myriad of possible implications of such process misrepresentation (or exclusion) on the treatment of convective stabilization and recovery by different convective parameterization schemes.

Acknowledgments. The authors are indebted to Purdue University upsonde crew members Dr. M. Baldwin and L. Dawson, the NSSL upsonde crews led by Drs. D. Stensrud and M. Coniglio, the CSU upsonde crews led by Dr. R. Schumacher, and the TAMU upsonde crews led by Dr. D. Conlee. Contributions to this research by J. Woznicki were supported in part by a Purdue Chappelle Fellowship, and by the National Science Foundation Grant AGS-106226, which also partially supported R. Trapp. Radiosonde data were reprocessed and quality controlled 
by NCAR/EOL, under sponsorship of the National Science Foundation. The CM1 model was graciously provided by Dr. G. Bryan (NCAR). Discussions with Drs. M. Baldwin, S. Lasher-Trapp, and S. Nesbitt helped improve this paper, as did the constructive comments offered by Dr. B. Mapes and the two anonymous reviewers.

\section{REFERENCES}

Adams-Selin, R. D., and R. H. Johnson, 2013: Examination of gravity waves associated with the 13 March 2003 bow echo. Mon. Wea. Rev., 141, 3735-3756, doi:10.1175/ MWR-D-12-00343.1.

Bretherton, C., 1993: The nature of adjustment in cumulus cloud fields. The Representation of Cumulus Convection in Numerical Models, Meteor. Monogr., No. 46, Amer. Meteor. Soc., 63-74.

-_, and P. K. Smolarkiewicz, 1989: Gravity waves, compensating subsidence, and detrainment around cumulus clouds. J. Atmos. Sci., 46, 740-759, doi:10.1175/1520-0469(1989)046<0740: GWCSAD $>2.0 . \mathrm{CO} ; 2$.

Brooks, H. E., C. A. Doswell III, and R. Davies-Jones, 1993: Environmental helicity and the maintenance and evolution of low-level mesocyclones. The Tornado: Its Structure, Dynamics, Prediction and Hazards, Geophys. Monogr., Vol. 79, Amer. Geophys. Union, 97-104.

Bryan, G. H., 2016: The governing equations for CM1. MMM/ UCAR, $17 \mathrm{pp}$. [Available online at http://www2.mmm.ucar. edu/people/bryan/cm1/cm1_equations.pdf.]

_, and J. M. Fritsch, 2002: A benchmark simulation for moist nonhydrostatic numerical models. Mon. Wea. Rev., 130, 2917-2928, doi:10.1175/1520-0493(2002)130<2917:ABSFMN>2.0.CO;2.

_ , and M. D. Parker, 2010: Observations of a squall line and its near environment using high-frequency rawinsonde launches during VORTEX2. Mon. Wea. Rev., 138, 4076-4097, doi:10.1175/2010MWR3359.1.

Del Genio, A. D., J. Wu, and Y. Chen, 2012: Characteristics of mesoscale organization in WRF simulations of convection during TWPICE. J. Climate, 25, 5666-5688, doi:10.1175/JCLI-D-11-00422.1.

Emanuel, K. A., 1994: Atmospheric Convection. Oxford University Press, $580 \mathrm{pp}$.

Fovell, R. G., 2002: Upstream influence of numerically simulated squall-line storms. Quart. J. Roy. Meteor. Soc., 128, 893-912, doi:10.1256/0035900021643737.

Klemp, J. B., and R. B. Wilhelmson, 1978: The simulation of three-dimensional convective storm dynamics. J. Atmos. Sci., 35, 1070-1096, doi:10.1175/1520-0469(1978)035<1070: TSOTDC $>2.0 . \mathrm{CO} ; 2$.

Lane, T. P., and M. J. Reeder, 2001: Convectively generated gravity waves and their effect on the cloud environment. J. Atmos.
Sci., 58, 2427-2440, doi:10.1175/1520-0469(2001)058<2427: CGGWAT $>2.0 . \mathrm{CO} ; 2$.

Mapes, B. E., 1993: Gregarious tropical convection. J. Atmos. Sci., 50, 2026-2037, doi:10.1175/1520-0469(1993)050<2026: GTC $>2.0 . \mathrm{CO} ; 2$.

- 1997: Equilibrium vs. activation control of large scale variations of tropical deep convection. The Physics and Parameterization of Moist Atmospheric Convection, R. K. Smith, Ed., Springer, 321-358.

Nicholls, M. E., R. A. Pielke, and W. R. Cotton, 1991: Thermally forced gravity waves in an atmosphere at rest. J. Atmos. Sci, 48, 1869-1884, doi:10.1175/1520-0469(1991)048<1869: TFGWIA $>2.0 . \mathrm{CO} ; 2$.

Nowotarski, C. J., and P. M. Markowski, 2016: Modifications to the near-storm environment induced by simulated supercell thunderstorms. Mon. Wea. Rev., 144, 273-293, doi:10.1175/ MWR-D-15-0247.1.

Parker, M. D., 2014: Composite VORTEX2 supercell environments from near-storm soundings. Mon. Wea. Rev., 142, 508529, doi:10.1175/MWR-D-13-00167.1.

Schlesinger, R. E., 1990: Feedback of deep moist convection to its near environment as diagnosed from three-dimensional numerical model output: Results from an early experiment. J. Atmos. Sci., 47, 1390-1412, doi:10.1175/1520-0469(1990)047<1390: FODMCT $>2.0 . \mathrm{CO} ; 2$.

Stensrud, D. J., G. S. Manikin, E. Rogers, and K. E. Mitchell, 1999: Importance of cold pools to NCEP mesoscale Eta Model forecasts. Wea. Forecasting, 14, 650-670, doi:10.1175/ 1520-0434(1999)014<0650:IOCPTN>2.0.CO;2.

Trapp, R. J., D. J. Stensrud, M. C. Coniglio, R. S. Schumacher, M. E. Baldwin, S. Waugh, and D. T. Conlee, 2016: Mobile Radiosonde Deployments during the Mesoscale Predictability Experiment (MPEX): Rapid and Adaptive Sampling of Upscale Convective Feedbacks. Bull. Amer. Meteor. Soc., 97, 329-336, doi:10.1175/BAMS-D-14-00258.1.

Weisman, M. L., and J. B. Klemp, 1982: The dependence of numerically simulated convective storms on vertical wind shear and buoyancy. Mon. Wea. Rev., 110, 504-520, doi:10.1175/ 1520-0493(1982)110<0504:TDONSC $>2.0 . C O ; 2$.

—_, and R. Rotunno, 2000: The use of vertical wind shear versus helicity in interpreting supercell dynamics. J. Atmos. Sci., 57, 1452-1472, doi:10.1175/1520-0469(2000)057<1452: TUOVWS $>2.0 . \mathrm{CO} ; 2$.

_ , and R. J. Trapp, 2003: Low-level mesovortices within squall lines and bow echoes. Part I: Overview and dependence on environmental shear. Mon. Wea. Rev., 131, 2779-2803, doi:10.1175/1520-0493(2003)131<2779:LMWSLA > 2.0.CO;2. , and Coauthors, 2015: The Mesoscale Predictability Experiment (MPEX). Bull. Amer. Meteor. Soc., 96, 2127-2149, doi:10.1175/BAMS-D-13-00281.1. 